\title{
Evaluation of Postgraduate Trainees' Satisfaction in Histopathology at A Tertiary Care Teaching Hospital - A Cross Sectional Study
}

\author{
B. Krishnamurthy ${ }^{1 *}$, B. Anuradha ${ }^{2}$, B.H.P Chandrasekhar ${ }^{3}$, D. Nagendraprasad ${ }^{4}$ \\ ${ }^{1,3,4}$ Assistant Professor, Department of Pathology, S.V. Medical College, Tirupati, Andhra Pradesh, India \\ ${ }^{2}$ Professor and HOD, Department of Pathology, S.V. Medical College, Tirupati, Andhra Pradesh, India
}

DOI: $10.36348 /$ sjpm.2020.v05i03.006 $\quad$ | Received: 04.03.2020| Accepted: 12.03.2020 | Published: 18.03 .2020

*Corresponding author: Dr. B. Krishnamurthy

\section{Abstract}

Background: Students' satisfaction reflects what they expect from their educational institution Until the 1980s, feedback from students about their experience in higher education was an uncommon practice. Student life is a network of academic and social interactions connected. Many colleges have comprehensive processes for achieving excellence or meeting high-quality standards, with "Student Satisfaction" at the heart of all higher education targets for excellence. Student's satisfaction reflects what they expect from their educational institution. Methods: This study is a cross-sectional descriptive study. The study population includes nine graduates of the MD pathology program who specialized in histopathology. The data was gathered through a structured questionnaire. Self-administered, closed-ended, unipolar 5grade Likert scale has been developed and validated to assess the level of satisfaction of histopathology graduates in 14 areas of the training program. Results: High satisfaction: Overall, the trainees expressed significant satisfaction with numerous training areas are entry exam (90\%), surgical pathology knowledge (80\%), surgical pathology skills (80\%), routine work $(90 \%)$, textbooks $(100 \%)$, teaching slides $(80 \%)$, local training courses $(80 \%)$, peer learning $(100 \%)$, weekly sessions (100\%), hand over (90\%). Conclusion: The students and trainees overall have a high level of satisfaction with postgraduate training in histopathology. This study can serve as a preliminary guide for potential reform of the histopathology training. Reform will lead to better training and better service.

Keywords: Histopathology, satisfaction, postgraduate trainees.

Copyright @ 2020: This is an open-access article distributed under the terms of the Creative Commons Attribution license which permits unrestricted use, distribution, and reproduction in any medium for non-commercial use (NonCommercial, or CC-BY-NC) provided the original author and sources are credited.

\section{INTRODUCTION}

Student life is a network of academic and social interactions connected. Many colleges have comprehensive processes for achieving excellence or meeting high-quality standards, with "Student Satisfaction" at the heart of all higher education targets for excellence. Student's satisfaction reflects what they expect from their educational institution [1].

Generally, the feedback in question takes the form of student ratings of their level of satisfaction or self-reporting of other attitudes towards their teachers or course units. The feedback is obtained through standard questionnaires, the answers are scanned automatically, and a descriptive summary of the answers is given to the relevant teacher [2].

Student feedback on their higher education experience was an unusual occurrence up until the 1980s. The 2000s witnessed significant concerns about quality \& student satisfaction, and feedback became an essential element of the management cycle of higher education [3].

The satisfaction of the students was related to their later professional attitudes, career commitment \& retention; professional education faculties should be concerned with the satisfaction of the students as a result of the educational process [4].

Data about the satisfaction of postgraduate students can be gathered through surveys of trainees and graduates. These data form constructive feedback to improve the quality of medical education and clinical education [5].

To this purpose we have studied evolution of postgraduate's trainee's satisfaction in histopathology at tertiary care teaching hospital 


\section{METHODS}

This study is a cross-sectional descriptive study. This study was carried in Narayana medical college, Nellore. The study population includes nine graduates of the MD pathology program who specialized in histopathology. The data was gathered through a structured questionnaire. Self-administered, closed-ended, unipolar 5-grade Likert scale has been developed and validated to assess the level of satisfaction of histopathology graduates in 14 areas of the training program. The attribute result was the degree of satisfaction and rated as follows: 1 , not satisfied at all; 2, mildly satisfied; 3, moderately satisfied; 4, very satisfied; 5, extremely satisfied. Graduates who responded with $3,4 \& 5$ are considered as satisfied, those who respond with $1 \& 2$ are considered as unsatisfied.

\section{RESULTS}

Ten out of the twelve MD graduates in histopathology responded to the questionnaire. The response rate was $83.3 \%$. Among them were four males $(40 \%)$ and six females $(60 \%)$. The age group ranged from 30 to 40 years. The response rate divided to high (> 76\%), moderate $(51 \%-75 \%)$ and low satisfaction $(<50 \%)$.

Table-1: Score \& percentages of satisfaction for the surveyed training areas

\begin{tabular}{|c|c|c|c|c|c|c|c|c|c|}
\hline \multirow[t]{2}{*}{ S.No } & \multirow[t]{2}{*}{ Questionnaire items } & \multicolumn{5}{|c|}{ Frequencies of satisfaction scores } & \multirow[t]{2}{*}{ Mean } & \multirow[t]{2}{*}{ SD } & \multirow[t]{2}{*}{ Percentage (\%) } \\
\hline & & 1 & 2 & 3 & 4 & 5 & & & \\
\hline 1 & Entry exam & 1 & 0 & 7 & 2 & 0 & 3 & 0.81 & $90 \%$ \\
\hline 2 & Part one course & 3 & 4 & 1 & 1 & 1 & 2.3 & 1.33 & $30 \%$ \\
\hline 3 & Induction & 7 & 1 & 2 & 0 & 0 & 1.5 & 0.84 & $20 \%$ \\
\hline \multirow[t]{2}{*}{4.0} & Surgical Path. knowledge & 0 & 2 & 6 & 2 & 0 & 3 & 0.66 & $80 \%$ \\
\hline & Surgical Path. skills & 0 & 2 & 6 & 1 & 1 & 3.1 & 0.87 & $80 \%$ \\
\hline \multirow[t]{2}{*}{4.1} & Cytology knowledge & 1 & 3 & 5 & 1 & 0 & 2.6 & 0.84 & $60 \%$ \\
\hline & Cytology skills & 2 & 3 & 4 & 1 & 0 & 2.4 & 0.96 & $50 \%$ \\
\hline 5.0 & Routine work & 0 & 1 & 0 & 4 & 5 & 4.3 & 0.94 & $90 \%$ \\
\hline 5.1 & Textbooks & 0 & 0 & 1 & 9 & 0 & 3.9 & 0.31 & $100 \%$ \\
\hline 5.2 & Teaching slides & 1 & 2 & 3 & 3 & 1 & 3.3 & 1.5 & $80 \%$ \\
\hline 5.3 & Local training courses & 1 & 1 & 6 & 1 & 1 & 3 & 1.05 & $80 \%$ \\
\hline 5.4 & Regional and international courses & 2 & 2 & 4 & 1 & 1 & 2.7 & 1.25 & $60 \%$ \\
\hline 5.5 & E-learning & 1 & 2 & 3 & 4 & 0 & 3 & 1.05 & $70 \%$ \\
\hline 5.6 & Peer learning & 0 & 0 & 3 & 5 & 2 & 3.9 & 0.73 & $100 \%$ \\
\hline 5.7 & Private labs\& clinics & 1 & 2 & 5 & 1 & 1 & 2.9 & 1.1 & $70 \%$ \\
\hline 5.8 & Weekly sessions & 0 & 0 & 0 & 1 & 9 & 4.9 & 0.31 & $100 \%$ \\
\hline 6 & Duration of rotation & 2 & 6 & 2 & 0 & 0 & 2 & 0.66 & $20 \%$ \\
\hline 7 & Organization & 0 & 5 & 3 & 2 & 0 & 2.7 & 0.82 & $50 \%$ \\
\hline 8 & Laboratory management & 2 & 3 & 5 & 0 & 0 & 2.3 & 0.82 & $50 \%$ \\
\hline 9 & Research experience & 0 & 3 & 5 & 2 & 0 & 2.9 & 0.73 & $70 \%$ \\
\hline 10 & Supervision & 1 & 4 & 3 & 2 & 0 & 2.6 & 0.96 & $50 \%$ \\
\hline 11 & Hand over & 0 & 1 & 5 & 2 & 2 & 3.5 & 0.97 & $90 \%$ \\
\hline 12 & Communication & 0 & 5 & 3 & 2 & 0 & 2.7 & 0.82 & $50 \%$ \\
\hline 13 & Professionalism & 2 & 6 & 0 & 0 & 2 & 2.2 & 1.03 & $20 \%$ \\
\hline 14 & Overall satisfaction & 0 & 4 & 4 & 0 & 2 & 3 & 1.15 & $60 \%$ \\
\hline
\end{tabular}

\section{High satisfaction}

Overall, the trainees expressed significant satisfaction with numerous training areas are entry exam (90\%), surgical pathology knowledge (80\%), surgical pathology skills $(80 \%)$, routine work $(90 \%)$, textbooks $(100 \%)$, teaching slides $(80 \%)$, local training courses $(80 \%)$, peer learning $(100 \%)$, weekly sessions $(100 \%)$, hand over $(90 \%)$.

\section{Moderate satisfaction}

Cytology knowledge (60\%), regional and international courses $(60 \%)$, e-learning $(70 \%)$, private labs\& clinics $(70 \%)$, research experience $(70 \%)$, overall satisfaction $(60 \%)$.

\section{Low satisfaction}

Part one course (30\%), induction $(20 \%)$, cytology skills $(50 \%)$, and duration of rotation $(20 \%)$, organization $(50 \%)$, laboratory management $(50 \%)$, and supervision (50\%), and communication (50\%), professionalism $(20 \%)$.

\section{DISCUSSION}

Extensive histopathology training is demanding and daunting concerning equipment, instruments, reagents, trained personnel, a variety of surgical and cytological specimens, operating in a multidisciplinary team setting, and keeping up with the latest developments in diagnostic tools and advanced technologies. 
Trainees in histopathology expressed a high level of satisfaction in many areas of the questionnaire. Our study is supported by Gamal M [6], Learning with Each Other: Peer Learning as an Academic Culture among Graduate Students in Education, a survey conducted on a sample of 375 graduate students in Saudi university education programs. The study key results showed a majority of respondents $(69 \%)$ agree and strongly agree, while (12.4\%) disagree and strongly disagree, and (21\%) disagree.

Burgess A [7] studied Medical students as peer tutors: a systematic review. Results from this review suggest that there are many perceived learning benefits for student tutors. However, there were mixed results regarding the accuracy of peer assessment and feedback, and no substantial evidence to conclude that participation as a peer tutor improves one's examination performance.

Joanna H [8] studied, medical students reported valuing and using Peer-assisted learning as a learning tool for clinical education. They said, on average, using PAL more than 20 times a week (approximately four times a day), although these practices were not required or encouraged by an instructor, nor included as part of the structured curriculum in a course guide.

Ali IS [9] studied about Trainees' feedback on the prevailing teaching methods in the postgraduate medical institute, Lady Reading Hospital, Peshawar, Pakistan. Of the total 268 trainees, the response rate was 260. Lecture / tutorials were recorded as the key teaching method by 239 (91.9\%), bedside teaching by $229(88.1 \%)$, journal club by $217(83.5 \%)$, e-learning by $157(60.4 \%)$, audit meetings by $152(58.5 \%)$, interactive sessions by $144(55.4 \%)$, radiology meeting by $101(38.8 \%)$ and TOACS by $39(15 \%)$ trainees. Concluded Lecture is the most commonly used method of teaching in the Lady Reading Hospital, Peshawar.

Celia C. Lo [10] conducted study, How student satisfaction factors affect perceived learning, concluded The study showed all of these satisfaction factors to be associated with higher rates of perceived learning, measured via students' expectations of academic success.

\section{CONCLUSION}

The students and trainees overall have a high level of satisfaction with postgraduate training in histopathology. This study can serve as a preliminary guide for potential reform of the histopathology training. Reform will lead to better training and better service.

Funding: No funding sources

Conflict of interest: None declared

Ethical approval: The study was approved by the Institutional Ethics Committee

\section{REFERENCES}

1. Al-Sheeb, B., Hamouda, A. M., \& Abdella, G. M. (2018). Investigating Determinants of Student Satisfaction in the First Year of College in a Public University in the State of Qatar. Education Research International, 2018.

2. Richardson, J. T. (2005). Instruments for obtaining student feedback: A review of the literature. Assessment \& evaluation in higher education, 30(4), 387-415.

3. Harvey, L. (2003). Student feedback [1]. Quality in higher education, 9(1), 3-20.

4. Ziaee, V., Ahmadinejad, Z., \& Morravedji, A. R. (2004). An evaluation on medical students' satisfaction with clinical education and its effective factors. Medical Education Online, 9(1), 4365.

5. Hollick, R. J., Ripley, D. P., \& Walesby, K. E. (2015). Shaping the future of our training. Journal of the Royal College of Physicians of Edinburgh.

6. Mustafa, G. M. (2017). Learning with each other: Peer learning as an academic culture among graduate students in education. American Journal of Educational Research, 5(9), 944-951.

7. Burgess, A., McGregor, D., \& Mellis, C. (2014). Medical students as peer tutors: a systematic review. BMC medical education, 14(1), 115.

8. Tai, J. H., Haines, T. P., Canny, B. J., \& Molloy, E. K. (2014). A study of medical students' peer learning on clinical placements: What they have taught themselves to do. Journal of Peer Learning, 7(1), 57-80.

9. Ali, I. S., Khan, M., Khan, A., Shah, M. F., \& Ali, G. (2012). Trainees' feedback on the prevailing teaching methods in postgraduate medical institute, Lady Reading Hospital, Peshawar, Pakistan. JCPSP, 22(5), 311-16.

10. Lo, C. C. (2010). How student satisfaction factors affect perceived learning. Journal of the Scholarship of Teaching and Learning, 47-54. 